\title{
Preparation and investigation of core-shell nanoparticles containing human interferon- $\alpha$
}

\author{
Katalin Kristóa $^{\mathrm{a}}$, Márta Szekeres ${ }^{\mathrm{b}}$, Zsolt Makai ${ }^{\mathrm{a}}$, Árpád Márki ${ }^{\mathrm{c}}$, András Kelemen ${ }^{\mathrm{d}}$, László Bali ${ }^{\mathrm{e}}$, \\ Zsolt Pallai ${ }^{\mathrm{e}}$, Imre Dékány ${ }^{\mathrm{b}, \mathrm{f}}$, Ildikó Csóka ${ }^{\mathrm{a}, *}$ \\ ${ }^{a}$ Institute of Pharmaceutical Technology and Regulatory Affairs, University of Szeged, Eötvös u. 6, H-6720 Szeged, Hungary \\ ${ }^{\mathrm{b}}$ Department of Physical Chemistry and Materials Science, University of Szeged, Aradi v.t.1, H-6720 Szeged, Hungary \\ ${ }^{c}$ Department of Pharmacodynamics and Biopharmacy, University of Szeged, Eötvös u. 6, H-6720 Szeged, Hungary \\ ${ }^{\mathrm{d}}$ Department of Applied Informatics, University of Szeged, Boldogasszony sgt. 6, H-6725 Szeged, Hungary \\ ${ }^{\mathrm{e}}$ Trigon Biotechnological Ltd., Bánk Bán u. 6, H-1115 Budapest Hungary \\ ${ }^{\mathrm{f}}$ Department of Medical Chemistry, University of Szeged, Dóm tét 8, H-6720 Szeged, Hungary
}

\section{A R T I C L E I N F O}

\section{Keywords:}

Interferon- $\alpha$

Human serum albumin

Core-shell nanoparticle

Layer-by-layer self-assembly

Polyelectrolyte multilayers

Sustained release

In vivo release study

\begin{abstract}
A B S T R A C T
Sustained release of active interferon- $\alpha(\operatorname{IFN}-\alpha)$ has been achieved from core-shell nanoparticles (NPs) prepared by aqueous precipitation of IFN- $\alpha$-enriched human serum albumin (HSA-IFN- $\alpha$ ) and layer-by-layer (L-b-L) by coating of the IFN- $\alpha$ NPs with poly(sodium-4-styrene) sulphonate (PSS) and chitosan (Chit). The concentration and the $\mathrm{pH}$ of HSA solution were optimized during the development of this method. Dynamic light scattering (DLS), zeta-potential, thermal analysis (differential scanning calorimetry (DSC) and termogravimetry (TG)), Xray diffraction (XRD), IFN- $\alpha$ activity and morphology (transmission electron microscope (TEM)) studies were used to control the preparation and analyse the products. The dissolution kinetics of NPs was measured in vitro over 7 days in Hanson dissolution tester with Millex membrane. In vivo studies in Pannon white rabbit detected steady IFN- $\alpha$ plasma level for 10 days after subcutaneous injection administration of the HSA-IFN- $\alpha$ NPs. The IFN- $\alpha$ plasma concentration was detected by using the enzyme-linked immunosorbent assay (ELISA) method. In the present paper we discuss the preparation method, the optimization steps and the results of in vitro and in vivo release studies. It was established that $76.13 \%$ HSA-IFN- $\alpha$ are encapsulated in the core-shell NPs.
\end{abstract}

\section{Introduction}

Interferons (IFNs) are cytokines that regulate the expression of genes determining cellular fate and anti-viral defense. IFN- $\alpha$ and IFN- $\beta$ represent class I IFNs. IFN- $\gamma$ defines class II IFN. Class III ( $\lambda$-IFNs) exerts biological properties reminiscent of that of IFN- $\alpha$ and IFN- $\beta$ (Pollok et al., 2013). IFNs can be considered as an effective adjuvant treatment for selected melanoma patients, although more refined algorithms are required to optimize its effectiveness (Di Trolio et al., 2015).

Drug formulation studies are centred around the spatial and kinetic control of drug release. Core-shell particles have become an important research area over past decades due to their great application potentials in fields like bio-imaging, controlled release, tumour therapy, tissue engineering, and so forth (Chen et al., 2010; Gao et al., 2013; Giri1 et al., 2011; He et al., 2015; Khdair et al., 2016; Lei et al., 2014; Li et al., 2018; Narayanan et al., 2014; Nie et al., 2010a; Nie et al., 2010b; Sedeky et al., 2018; Yang et al., 2013; Wang et al., 2012; Wu et al.,
2011). Among the various formulation possibilities colloidal methods provide the largest variability regarding particle size, pore structure, solvation and charge properties of the surface, $\mathrm{pH}$ - and ionic strength dependence of specific functional groups (Zashikhina et al., 2017). Exploiting self-ordering and self-organizing properties of colloids, more complex structures can also be prepared. One of the smart colloidal drug carrier formulations is layer-by-layer (L-b-L) construction of multiple molecular sheets at surfaces of colloidal nano and microparticles (Borkovec and Papastavrou, 2008; Kotov et al., 1995; Martinek et al., 2006; Möhwald, 2000; Radtchenko et al., 2000; Sukhorukov et al., 1998; Zhao et al, 2018). This method, worked out originally for preparation of multilayered nanostructures on flat macroscopic or colloidal surfaces, is also called electrostatic self-assembly (ESA). The multilayered polyelectrolyte coatings serve as membranes, the designed pores of which can entrap or transmit drug molecules, or to retard their diffusion. Various types of polyelectrolyte multilayers have been prepared on the surface of microscopic particles

\footnotetext{
* Corresponding author.

E-mail address: csoka@pharm.u-szeged.hu (I. Csóka).
} 
(Balabushevitch et al., 2001; Caruso et al., 2000; Freag et al., 2018; Ke et al, 2018), but NP coating by L-b-L shells is rare in the literature. Soft larger particles or small particles with thick soft coating are also able to penetrate endothelia. In addition, some injectable formulations for sustained release also need to be prepared from nanoscale particle dispersions. The duration of sustained drug release from the nano or microcarrier systems is usually not longer than several tens of hours (de Villiers et al., 2011).

Microparticles are frequently used to prepare capsules into which drug molecules can be filled in a separate infiltration step. The polyelectrolyte layers are permeable and various drug molecules can be infiltrated into the capsules via simple diffusion process. H. Möhwald and co-workers prepared micrometer-sized (10 $\mu \mathrm{m}$ diameter) enzyme crystals coated with polyelectrolyte multilayers (Balabushevitch et al., 2001; Caruso et al., 2000), and the enzyme retained biological activity. Polyelectrolyte microcapsules were also formed on melamine formaldehyde microparticles, for subsequent infiltration of active agents (Ai et al., 2005).

For several years, large molecules such as proteins were not considered applicable for controlled release systems, because they are too large to diffuse through most polymeric materials (Dai et al., 2005; Sinha and Trehan, 2003; Yu et al., 2016). After the breakdown of this presumption many polymers have been used as delivery vehicles for insulin, growth factors, angiogenesis inhibitor proteins or protein kinase C inhibitor (Liu et al, 2019; Shkodra-Pula et al., 2019). Proteins are very sensitive to environmental conditions. Changes in $\mathrm{pH}$, temperature, salinity, or the presence of complexing agents or cosolvents can easily lead to denaturation and inactivation (Kim et al., 2015).

Protein microparticles have also been prepared by the emulsion or double emulsion method (Duncana et al., 2005). Core-shell structured protein microparticles resulted also in the adsorption of a protein active agent on porous $\mathrm{CaCO}_{3}$ particles (Volodkin et al., 2004) coated subsequently with polyelectrolytes, after which the inorganic template was extracted. The dissolution of the template risks protein denaturation. In the case of microcapsules, the protein must be loaded into the emptied capsules, but the efficiency of infiltration is usually very low. Jörgensen et al. (2006) analysed the methods of protein formulations (microspheres, emulsions, hydrogel based macroparticles) and revealed that many important questions such as formulation stability, complete drug release, shelf stability, are not yet resolved.

In the present work, protein NPs were prepared for sustained release of IFN- $\alpha$. Nowadays, the administration route of IFN- $\alpha$ is frequent injection of the dissolved protein, because it is a very sensitive material. The frequent injections have disadvantages such as low patient compliance because of the pain they cause. One of the solutions can be the application of oral delivery of the IFN- $\alpha$ (as a chemotherapeutic agent) (Caldorera-Moore et al., 2019). Patient compliance can also be increased with application of sustained release injection, for which the administration frequency is considerably lower. The solid core of the NPs was prepared by precipitation of HSA-IFN- $\alpha$ with salt. The NPs were subsequently coated by polyelectrolyte multilayers using the ESA method, or L-b-L self-assembly.

In our previous study bovine serum albumin (BSA) based core-shell NPs were developed as carrier systems for drug transportation. At $\mathrm{pH}=3$, the oppositely charged polyelectrolytes: poly(sodium-4styrene) sulphonate (PSS) and the chitosan (Chit) was bound to the positively charged protein via electrostatic interactions. Ibuprofen was applied as model molecule which has low solubility (Varga et al., 2014). The aim of our work is to achieve sustained IFN- $\alpha$ release for 10 days after injection and test it in animal trials.

\section{Materials}

Human serum albumin (HSA) (Trigon Biotechnology Rt., Hungary) with isoelectric point, $\mathrm{pH}_{\mathrm{iep}}=4.8$ (Müller et al., 2004), as model protein and, human serum albumin enriched in recombinant human interferon- $\alpha$ (HSA-IFN- $\alpha$ ) (Trigon Biotechnology Rt., Hungary) were obtained as solutions in phosphate buffer (PBS, $\mathrm{pH}=6.8$ ) from Trigon Biotechnology Rt. (Hungary), and used without further purification. Poly(sodium-4-styrenesulphonate) (PSS) (Mw $=70,000 \mathrm{Da}$ ) (SigmaAldrich), low molecular weight chitosan (Chit) (DD > 75\%, Brookfield viscosity $20.000 \mathrm{cps}$ ) (Sigma-Aldrich), acetic acid (Molar Chemicals, Hungary) and the precipitating salt $\mathrm{Na}_{2} \mathrm{SO}_{4}$ (Sigma-Aldrich) were used without further purification. Ultrapure water was used throughout the experiments (MilliQ RG system, Millipore), and all the solutions were filtered through Millipore syringe filters of $0.22 \mu \mathrm{m}$ pore diameter before use. For the determination of protein concentration in the aliquot after dissolution test Bicinchonic Acid Kit (Sigma-Aldrich) was used.

\section{Methods}

\subsection{Preparation of core-shell NPs}

First step of the core-shell NP preparation was the precipitation of HSA-IFN- $\alpha$ from its buffered solution. The bare NPs should retain their IFN- $\alpha$ content and HSA solubility in order to release the IFN- $\alpha$ on administration. To satisfy these requirements, we applied the method of salting out by using multivalent ions. The mechanism of globular HSA precipitation by multivalent ions is basically charge screening and/or bridging through the multivalent ion. The electrokinetic potential of the precipitated particles reveals, which of them is effective. In the charge screening mechanism, the particle charge must reverse, or at least get neutralized, depending on the valence of the coagulating ion. On the other hand, bridging does not require complete neutralization. Specific effects, leading to the Hoffmeister series salting in and salting out effects, also play a role (Shih et al., 1992; Shiau and Chen, 1997).

The control parameters of the NP synthesis were: precipitation efficiency, average particle size, electrokinetic potential of the particles, and dissolution efficiency on dilution. Below the isoelectric point of HSA ( $\mathrm{pH} \leq 4.8)$, sulphate anions were used as effective precipitating ions in the form of saturated sodium salt. We have observed the formation of HSA NPs using $\mathrm{Na}_{2} \mathrm{SO}_{4}$, but not with two-valent cations. Hydrolysing cations did not precipitate HSA, since negatively charged metal hydroxides formed at high $\mathrm{pH}$, which could not bind the also negatively charged HSA.

NPs containing HSA and HSA-IFN- $\alpha$ were prepared. During the preparation the first step was the protein precipitation with $\mathrm{Na}_{2} \mathrm{SO}_{4}$ solution. $15 \mathrm{ml}$ of HSA solution at $3.9 \mathrm{w} / \mathrm{v} \%$ concentration was acidified to $\mathrm{pH}=3$ with acetic acid and precipitated with $3 \mathrm{ml}$ of $\mathrm{Na}_{2} \mathrm{SO}_{4}$ solution of $2 \mathrm{M}$ concentration. The resulting particles were separated by centrifuging in a Hettich Universal 30F (Hettich FurnTech GmbH, Germany) table top centrifuge. The second main step was the preparation of the layers (PSS/Chit/PSS). After optimization, the PSS and Chit concentrations were chosen as $0.3 \mathrm{w} / \mathrm{v} \%$ and the $\mathrm{pH}$ was set to 3 by acetic acid. The precipitated HSA-IFN- $\alpha$ was redispersed in $10 \mathrm{ml}$ of the polyelectrolyte solutions followed by continuous stirring for $1 \mathrm{~h}$. The samples were centrifuged after each polyelectrolyte layer binding step. Method procedure is presented schematically in Fig. 1. Each step of the process was accompanied by a series of quality control analyses (supernatant HSA concentration, DLS, and zeta potential determination). Finally, the HSA-IFN- $\alpha$ core-shell NPs were lyophilized.

\subsection{Optimization of the precipitation conditions of HSA}

For NPs preparations, the mild wet sol-gel method and the electrostatic adsorption mechanism were exploited. The precipitation kinetics was measured by using transmission spectroscopy at $\lambda=700 \mathrm{~nm}$ (Carl Zeiss photometer, Jena, Germany), and for salt dosing a Radelkis OP-930 Autoburette (Radelkis, Hungary) was used. The volume of the precipitating $\mathrm{Na}_{2} \mathrm{SO}_{4}$ solution of $2 \mathrm{M}$ had been optimized. The HSA concentration was $3.9 \mathrm{w} / \mathrm{v} \%$ and the volume was $15 \mathrm{ml}$. 


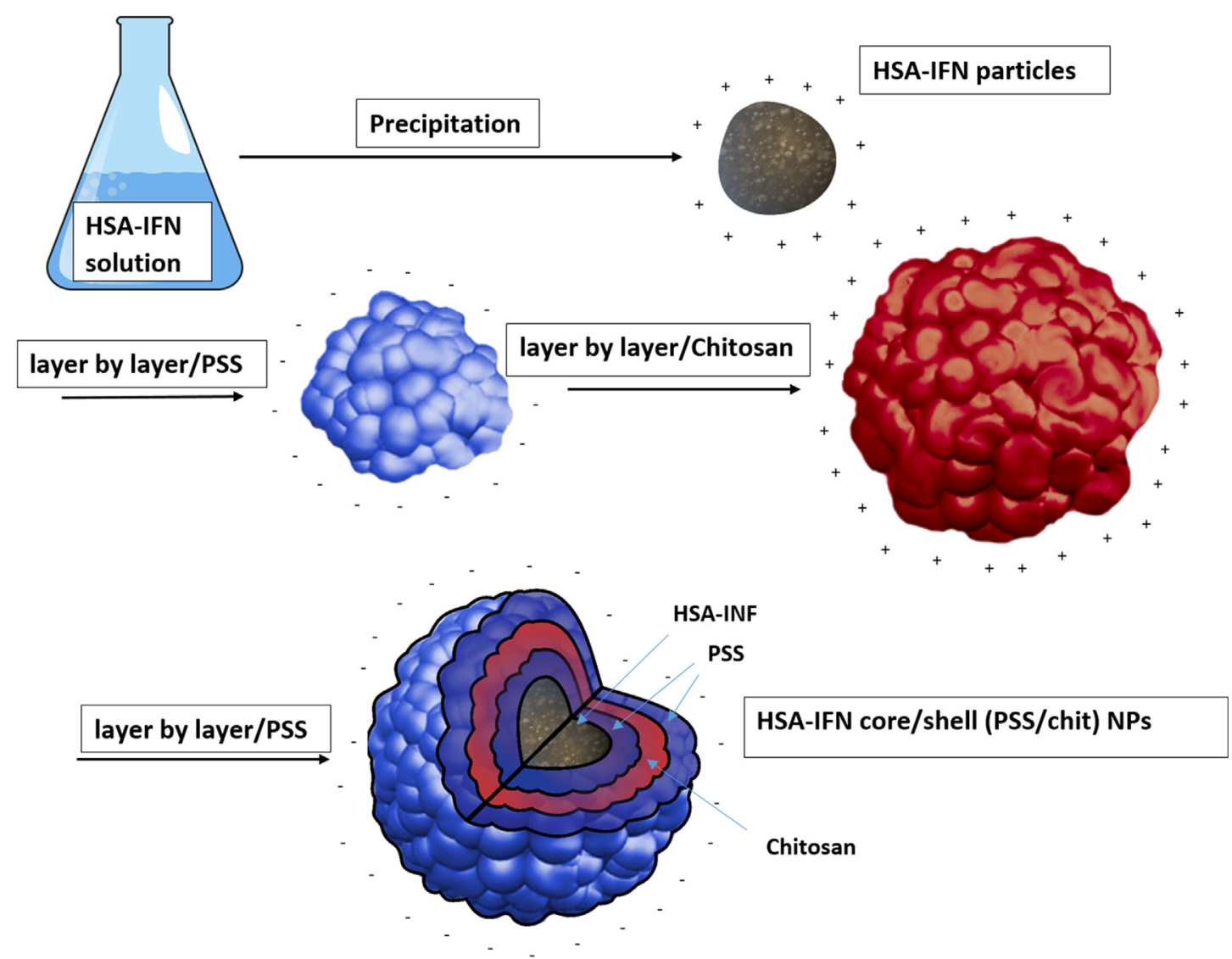

Fig. 1. Preparation scheme of the HSA-IFN- $\alpha$ core-shell NPs.

\subsection{Investigation of HSA precipitation efficiency with UV-VIS spectroscopy}

In the course of precipitation, the concentration of HSA was measured in the supernatant after centrifugation with UV-VIS spectroscopy at pHs 2.7, 2.8, 2.9 and 3. The HSA concentration of the supernatants was also measured by UV-VIS spectroscopy after each steps of polyelectrolyte multilayer build-up. HSA has an absorption peak at $278 \mathrm{~nm}$, and PSS at $260 \mathrm{~nm}$. The calibrations are measured both at $\lambda=278$ and $260 \mathrm{~nm}$ for each solute to obtain the actual extinction coefficients $(\varepsilon)$. The concentrations of HSA in the supernatants were calculated.

\subsection{Zeta-potential and dynamic light scattering measurements}

The particles were characterized by the particle size distribution from dynamic light scattering (DLS) measurements and by the electrokinetic potential from zeta potential $(\zeta)$ measurements in a Malvern Zetasizer Nano ZS apparatus (Malvern Instruments Ltd., UK). The zeta potential of the HSA NPs was positive, suggesting that the particles are formed primarily due to sulphate anion bridging thus the original positive electrokinetic potential of the dissolved protein molecules is retained. This condition is optimal for the electrostatic adsorption of anionic polyelectrolyte PSS. The HSA NPs are prepared at $\mathrm{pH}=3$. At the low pH only strong polyelectrolytes are fully dissociated, and PSS had been chosen for the core-shell NPs preparation for this reason. For optimization of PSS coating, the concentration of PSS solutions were between 0.0005 and $1 \mathrm{w} / \mathrm{v} \%$ and the $\mathrm{pH}$ was set to 3 by acetic acid.

\subsection{Measurement of streaming potential}

Particle charged detector (Mütek PCD-03, BTG Mütek GmbH, Germany) was used to measure the equivalence point of charge reversal of PSS coated NPs during titration with Chit. The concentration of Chit solutions was between 0.005 and $0.5 \mathrm{w} / \mathrm{v} \%$ and the $\mathrm{pH}$ was also set to 3 by acetic acid.

\subsection{Characterization of the HSA-IFN- $\alpha$ core-shell NPs}

3.6.1. Calculation of encapsulation efficiency (EE\%) and the loading capacity (LC\%)

Encapsulation efficiency was calculated from the UV spectra of the supernatant after every centrifugation step during preparation. Encapsulation efficiency (EE\%) by the adsorptions of PSS and Chit on the HSA-IFN- $\alpha$ composite was calculated according to the following equation (Eq. (1)):

$$
\begin{aligned}
& \text { (total amount of HSA IFN (mg) - amount of HSA } \\
& E E \%=\frac{I F N \alpha \text { in the supernatant sol. }(m g)}{\text { total amount of HSA IFNa (mg) }} \\
& \text { * } 100
\end{aligned}
$$

The loading capacity was also calculated (LC\%) (Eq. (2)):

$L C \%=\frac{\text { total entrapped HSA IFNa }(\mathrm{mg})}{\text { amountofpolyelectrolyte }(\mathrm{mg})+\text { entrappedHSAIFN }(\mathrm{mg})} * 100$

\subsubsection{Thermal analysis}

Differential scanning calorimetry (DSC) and termogravimetric (TG) (Mettler Toledo TGA/SDTA 851e and DSC 822e) analysis was used for the experiments. The temperature interval was $25-300^{\circ} \mathrm{C}$, and the heating rate was $4^{\circ} \mathrm{C} / \mathrm{min}$.

\subsubsection{X-ray diffraction (XRD)}

The degree of crystallinity of the freeze dried powder samples was 
checked by application of x-ray diffractometer (Philips PW 1830 Diffractometer) using K $\alpha$ radiation at a voltage of $40 \mathrm{kV}$ and a current of $35 \mathrm{~mA}$.

\subsubsection{Transmission electron microscopy (TEM)}

The particle size and shape was also inspected by using transmission electron microscopy (TEM, Philips CM-10).

\subsection{In vitro antiviral activity measurement}

In vitro antiviral activity of IFN- $\alpha$ released from the HSA-IFN- $\alpha$ NPs was measured using WISH tissue culture, Vesicular Stomatitis virus and $\mathrm{NIH}, \mathrm{Ga} 23-902-530 \mathrm{Hu}$ IFN- $\alpha$ standard. The antiviral activity of the original HSA-IFN- $\alpha$ was measured between $1.63 * 10^{5}-1.92 * 10^{5} \mathrm{IU} / \mathrm{mg}$. As the effective IFN- $\alpha$ content cannot be measured in the final coreshell NPs therefore the antiviral activity was determined.

\subsection{In vitro dissolution study}

Hanson Research SR8-Plus Dissolution Test Station (Hanson Reserch Corporation, USA), was used for the in vitro dissolution study. Millex GP 0.22 membrane (Merck Millipore, Dublin, Ireland) was applied for the separation of encapsulated IFN- $\alpha$ in NP dispersion. The mixing was continuous at $100 \mathrm{rpm}$. The dissolution media was $50 \mathrm{ml}$ PBS (phosphate buffer solution, $\mathrm{pH}=6.8$ ) at $36^{\circ} \mathrm{C}$. The duration was $144 \mathrm{~h}$ (6 day). On the first day, $1 \mathrm{ml}$ aliquots were taken every $30 \mathrm{~min}$ in the course of $2 \mathrm{~h}$, then once in $4 \mathrm{~h}$. Next 3 days aliquots were taken five times then on the 6 th day once $(144 \mathrm{~h})$. The volumes of the aliquots were refilled with PBS after each samplings. There were 6 parallel measurements. The protein concentration in the aliquots were determined by Bicinchoninic Acid Kit (Sigma-Aldrich) and by UV-VIS spectrophotometry (Helios $\alpha$, Unicam Spectronic, UK) at $562 \mathrm{~nm}$.

For the interpretation of dissolution model, the Sigma Plot 12.0 for Windows (Systat Software, Inc.) software was applied. The correlation coefficients $\left(R^{2}\right)$, the rate constant $(k)$ and the release exponent $(n)$ of models were calculated. The Korsmeyer-Peppas model, a semiempirical model that can be used to analyze data on drug release from polymers (Peppas, 1985), implies that the fractional release of drug is exponentially related to the release time, i.e., a power law equation: Eq. (3). The mathematical model used to fit this profile was the KorsmeyerPeppas or power low model equation by Sigma Plot 12.0 for Windows. In the case of first order model the drug activity within the reservoir is assumed to decline exponentially and the release rate is proportional to the residual activity: Eq. (4).

Korsmeyer - Peppas $\backslash$;model:Mt $/ M_{\infty}=k t^{n}$

First $\mid$;order $\backslash$ model $: M t / M \infty=1-\exp (-k t)$

where $M t / M \infty$ is a fraction of drug released at time $t, k$ is the rate constant, and $\mathrm{n}$ is the release exponent (Table 1).

\subsection{In vivo study}

In vivo IFN- $\alpha$ blood levels were determined in rabbits after subcutaneous administration of the drug formulations to Pannon white rabbits, using the human IFN- $\alpha$ ELISA kit (BMS216CE) of Bender

Table 1

Characterization of Exponent of Korsmeyer-Peppas Equation (Kelemen, 2012; Korbely et al., 2012).

\begin{tabular}{ll}
\hline Release exponent (n) & Drug transport mechanism \\
\hline 0.5 & Fickian diffusion \\
$0.5<\mathrm{n}<1$ & Non-Fickian transport \\
1 & Case II transport \\
$\mathrm{n}>1$ & Super case II transport
\end{tabular}

MedSystems (Wien, Austria), according to the procedure given by the producer. Following the administration of IFN- $\alpha$, blood samples were taken from the rabbits daily and the IFN- $\alpha$ level was determined. Egiferon $3 \cdot 10^{6} \mathrm{IU}$ injection was used as control, which contains the same HSA-IFN- $\alpha$ preparation as the starting material for NP formulations. The mean residence time (MRT) (Eq. (5)) and the elimination half-life time $\left(t_{1 / 2}\right)$ (Eq. (6)) were calculated by the following equations:

$M R T=\frac{A U M C_{0 \rightarrow 24}}{A U C_{0 \rightarrow 24}}$

where $A U M C$ is the area under the first moment curve or the curve of concentration*time versus time, and AUC is the area under the concentration versus time curve

$t_{1 / 2}=\ln 2 * M R T$

\section{Results and discussion}

\subsection{Optimization of the precipitation conditions of HSA}

The conditions of precipitation by $\mathrm{Na}_{2} \mathrm{SO}_{4}$ were optimized as follows. The volume of $2 \mathrm{M} \mathrm{Na}_{2} \mathrm{SO}_{4}$ solution was varied between 0.3 and $3 \mathrm{ml}$, leading to final concentrations between 0.06 and $0.4 \mathrm{M}$. The time of precipitation decreased from $130 \mathrm{~min}$ to $9 \mathrm{~min}$, and the precipitation efficiency increased from 40 to $96 \%$ with increasing total amount of $\mathrm{Na}_{2} \mathrm{SO}_{4}$ (Fig. 2). However, independent of the above variables, the particle size was $10 \pm 5 \mathrm{~nm}$ as obtained from number distribution in DLS measurements and the $\zeta$ potential was $+15 \pm 5 \mathrm{mV}$ in all experiments. $3 \mathrm{ml}$ of $2 \mathrm{M} \mathrm{Na}_{2} \mathrm{SO}_{4}$ was chosen for further experiments.

$\mathrm{pH}$ of the HSA solution was set to $\mathrm{pH}$ between 2.7 and 3, using acetic acid. pH 3 was chosen because the too low $\mathrm{pH}$ can cause a decrease in enzyme activity and a change in the structure of the protein. Under $\mathrm{pH} 2.7$ the protein is in a fully extended form (E) (Kun et al., 2009; Varga et al., 2016). The i.e. p. is around pH 4.7, therefore the selected $\mathrm{pH}$ must be lower than this value because in this range the charge of albumin is positive and higher than $\mathrm{pH}$ 2.7. Therefore the potential $\mathrm{pH}$ was between 2.7 and 4.7. After the measurement of the UV spectra of the supernatant (Fig. 3), the efficiency of precipitation was calculated and it can be seen in the case of $\mathrm{pH} 3$ this value was higher than $60 \%$ (61. 31\%). Therefore it can be an optimal pH because the HSA is not in E (extended) form and the precipitation efficiency is still acceptable.

The set of precipitation optimization experiments led to the following optimal conditions of HSA nanoparticle precipitation, which we applied also for precipitation of HSA-IFN- $\alpha$ :

$\mathrm{pH}=3$, set by acetic acid solution,

concentration of HSA-IFN- $\alpha, \mathrm{c}_{\mathrm{HSA}}=3.9 \mathrm{w} / \mathrm{v}$,

concentration of added $\mathrm{Na}_{2} \mathrm{SO}_{4}, \mathrm{c}_{\mathrm{Na} 2 \mathrm{SO} 4,0}=2 \mathrm{M}$ and

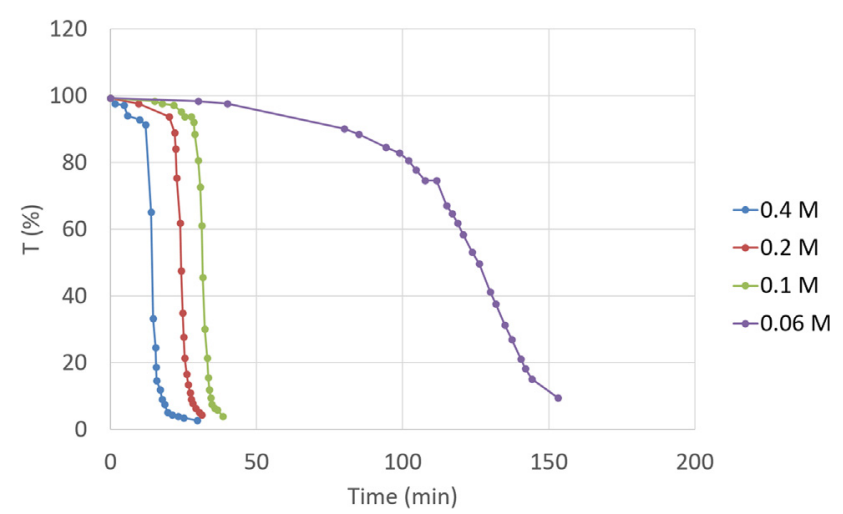

Fig. 2. Changes in the transmittance (T) of HSA solutions in the course of precipitation using $\mathrm{Na}_{2} \mathrm{SO}_{4}\left(10 \mathrm{ml}, \mathrm{pH}=3 ; 3.9 \mathrm{w} / \mathrm{v} \% \mathrm{HSA} ; 2 \mathrm{M} \mathrm{Na}_{2} \mathrm{SO}_{4}\right)$ as function of time at various $\mathrm{Na}_{2} \mathrm{SO}_{4}$ final concentrations. 


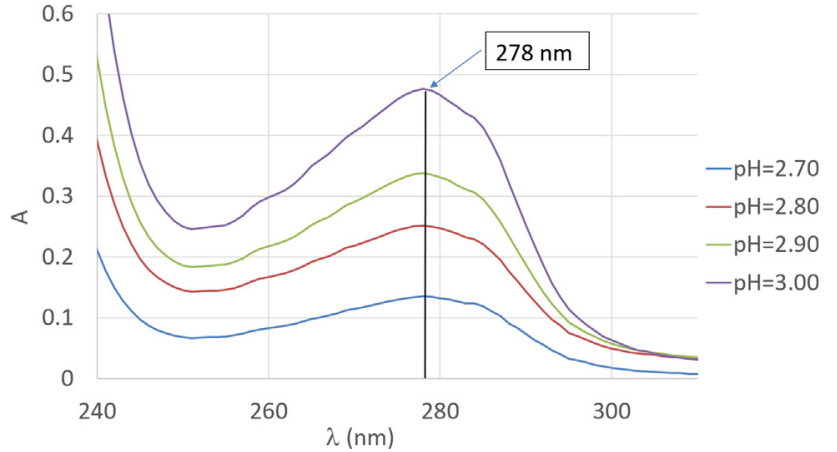

Fig. 3. Absorption spectra of HSA in the supernatant of HSA NPs precipitated by $\mathrm{Na}_{2} \mathrm{SO}_{4}$ ( $2 \mathrm{ml}$ solution of $2 \mathrm{M}$ concentration) at different pHs as measured after centrifugation.

final concentration of $\mathrm{Na}_{2} \mathrm{SO}_{4}, \mathrm{c}_{\mathrm{Na} 2 \mathrm{SO} 4, \mathrm{f}}=0.33 \mathrm{M}$.

\subsection{Optimization of the concentration and amount of polyelectrolytes for HSA NP coating}

UV-VIS spectrophotometry was used to determine the appropriate amount of PSS to coat quantitatively the preformed HSA NPs. Excess amount of free PSS in the supernatant of PSS-coated HSA NP dispersions appears in the spectra as a peak at $260 \mathrm{~nm}$ and that of HSA at $278 \mathrm{~nm}$. The UV-VIS spectrophotometry results (Fig. 4.) show that the HSA peak disappears gradually and the PSS peak appears with increasing PSS addition to the dispersion of precipitated HSA NPs $\left(\mathrm{v}=10 \mathrm{ml}, \mathrm{c}_{\mathrm{HSA}}=3.9 \mathrm{w} / \mathrm{v} \%\right.$ ). All HSA in the dispersion becomes buried under the PSS shell and settled out with centrifuging at PSS concentrations between 0.05 and $0.5 \mathrm{w} / \mathrm{v} \%$, therefore, its optimal concentration is found within this range. The adsorption of PSS results in charge reversal, seen in Fig. 5 as a sharp change of the zeta potential from +20 to $-50 \mathrm{mV}$ in a narrow PSS concentration range, accompanied by the sharp increase in the particle diameter to $\sim 10$ to $\sim 100 \mathrm{~nm}$. Based on the particle size and zeta potential experiments the necessary amount of PSS for HSA coating under the given conditions (i.e., volume and $\mathrm{pH}$ of the HSA NP dispersion, HSA concentration and precipitation conditions) is $0.25 \mathrm{w} / \mathrm{v} \%$.

Cationic Chit is adsorbed subsequently on the anionic PSS coated HSA NPs at $\mathrm{pH}=3$, to form the HSA/PSS/Chit NPs. The Chit concentration necessary to surface saturation and overcharge the HSA/PSS particles in $3 \mathrm{w} / \mathrm{v} \%$ dispersion was $\sim 0.3 \mathrm{w} / \mathrm{v} \%$ as obtained from PCD potential measurements demonstrated in Fig. 6.

\subsection{Characterisation of NPS}

The final HSA recovery after the nanoparticle precipitation and PSS-

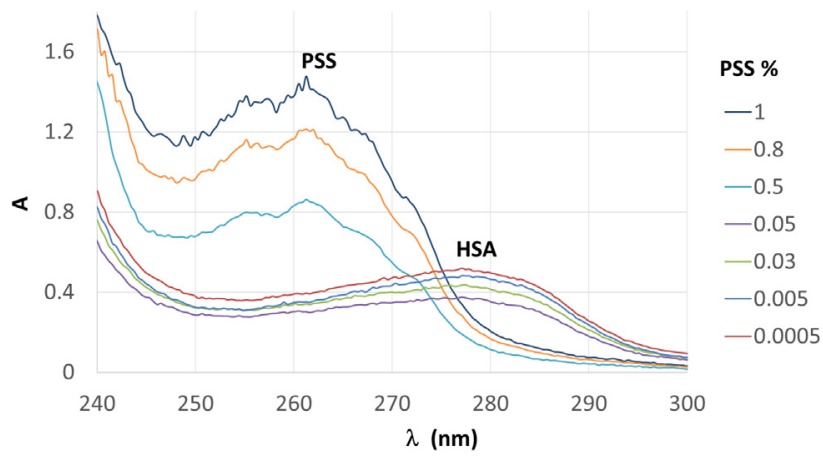

Fig. 4. The absorption spectra of a HSA Np dispersion supernatant after centrifugation as measured at different concentration of added PSS (volume of dispersion is $10 \mathrm{ml}, \mathrm{pH}=3$, $\mathrm{HSA}$ precipitated with $\mathrm{Na}_{2} \mathrm{SO}_{4}$ solution).

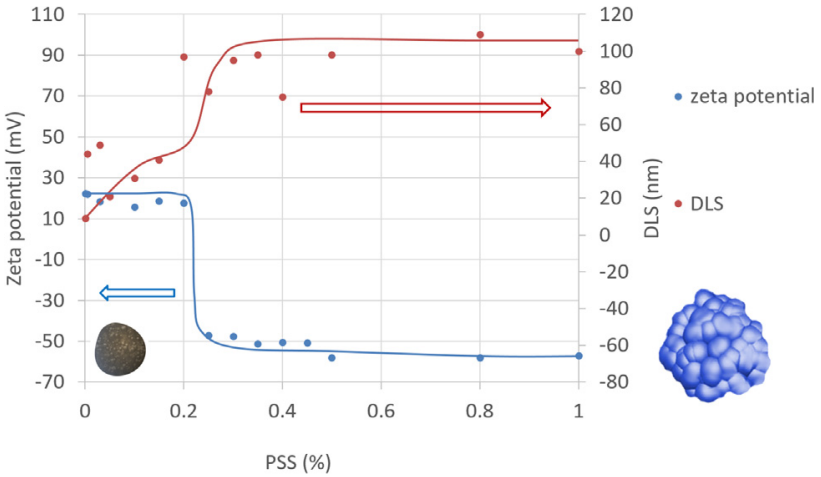

Fig. 5. Changes in zeta potential and hydrodynamic diameter of precipitated HSA NPs after with increasing concentration of added PSS at $\mathrm{pH}=3$ and HSA concentration of $3 \mathrm{w} / \mathrm{v} \%$

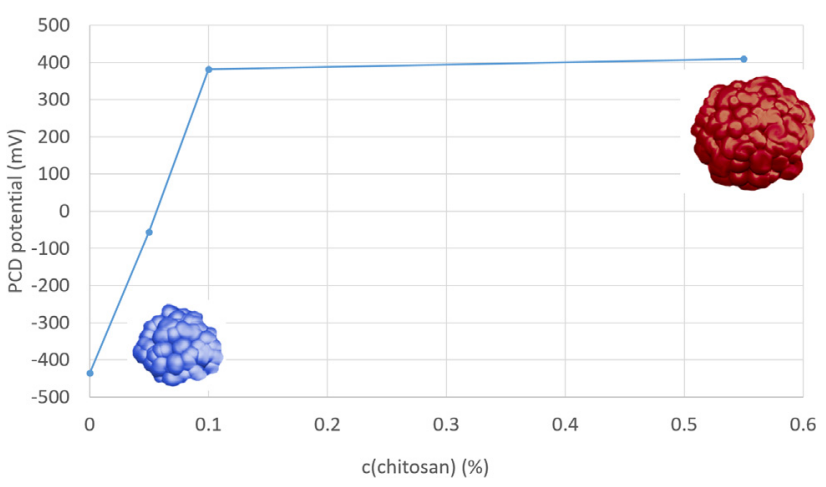

Fig. 6. Streaming potential change of the original HSA/PSS NPs during titration with chitosan solution at $\mathrm{pH}=3$, as measured by using Particle Charged Detector instrument (PSS at $\mathrm{pH}=3$ and HSA/PSS concentration of $3 \mathrm{w} / \mathrm{v} \%$ ).

coating was obtained from the analysis of UV-VIS spectra of the supernatants after each centrifugation step. After the precipitation step the yield was $60 \%$. On average, the encapsulation efficiency HSA-IFN- $\alpha$ core-shell NPs that retained $49.1 \%$ of the original amount of HSA-IFN$\alpha$. The procedures applied are small-scale laboratory production methods with relatively large loss percentage, meaning that scaling up to industrial size could result in higher encapsulation efficiency.

Knowing the concentration values and the volume of solutions the amount of HSA-IFN- $\alpha$ content was the differences between the original and equilibrium data. The difference of these data and the total amount of HSA-IFN- $\alpha(585 \mathrm{mg}$ ) was the total entrapped HSA-IFN- $\alpha$ amount: $287 \mathrm{mg}$. Encapsulation efficiency (EE\%) by the adsorptions of PSS and Chit on the HSA-IFN- $\alpha$ composite was calculated according to the following equation (Eq. (1)):

$E E \%=\frac{(585 \mathrm{mg}-298 \mathrm{mg})}{585 \mathrm{mg}} * 100=49.1 \%$

The HSA-IFN- $\alpha$ /polyelectrolyte (PSS/Chit/PSS) ratio was $287 \mathrm{mg} /$ $90 \mathrm{mg}=3.19$. This value is very high because of the high amount of HSA applied as carrier.

The loading capacity was also calculated (LC\%) (Eq. (2)):

$$
\begin{aligned}
L C \% & =\frac{287 \mathrm{mg} \text { (entrapped HSA IFN } \alpha)}{90 m g(\text { polyelectrolyte })+287 \mathrm{mg}(\text { entrapped HSA IFN })} * 100 \\
& =76.13 \%
\end{aligned}
$$

This $76.13 \%$ relates to the total HSA-IFN- $\alpha$ content of the core-shell NPs.

Figs. 7 and 8 give a representative example of changing the particle size distribution and zeta potential of the particles in the process of L-b$\mathrm{L}$ coating with anionic and cationic polyelectrolyte layers starting from the bare HSA nanoparticle.

It is clearly seen in Fig. 7 that the hydrodynamic diameter of the 


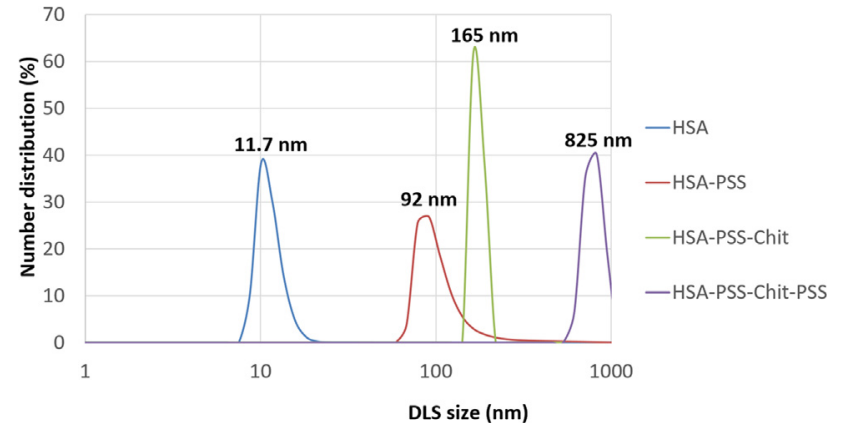

Fig. 7. Changes in the particle size with build-up of subsequent polyelectrolyte layers on the bare HSA NP surface as measured by DLS and analysed according to the number-distribution method.

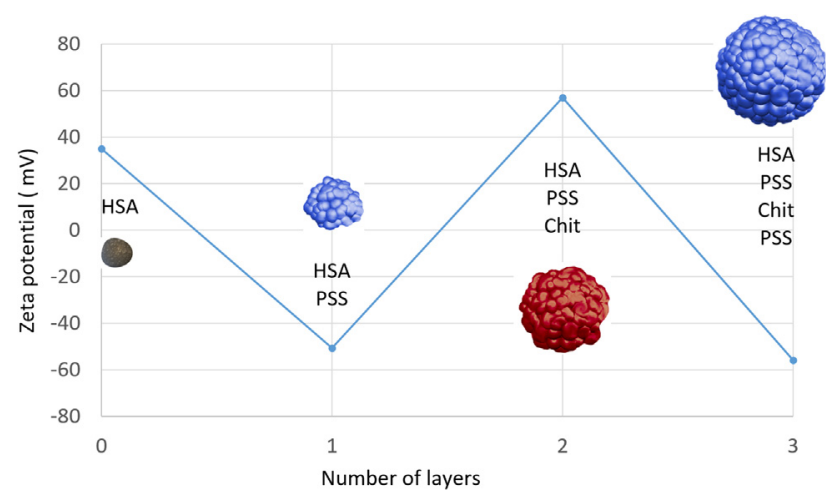

Fig. 8. Determination of the zeta potential of the corresponding types of HSA and core-shell HSA NPs.

originally precipitated bare HSA NPs is around $10 \mathrm{~nm}$, and the size increases stepwise with building up of subsequent layers of the polyelectrolyte shell. The diameter of the final particle type applicable for preparation of sustained release IFN- $\alpha$ formulation (i.e., HSA-IFN- $\alpha$ core-shell NP) is almost one micrometer; but as the shell around the solid core is flexible the particles can be expected to diffuse in the smaller capillaries despite of their larger size. The effective build-up of the alternate polyelectrolyte layers is proven unambiguously by the alternate positive and negative values of the zeta potential (Fig. 8).

The thermal stability of components and HSA core-shell NPs was investigated with TG (not shown here) and DSC. The adsorbed water evaporated from the precipitated HSA and the HSA-IFN- $\alpha$ core-shell NPs at lower temperature $\left(50-70{ }^{\circ} \mathrm{C}\right)$ than from the lyophilized HSA $\left(95^{\circ} \mathrm{C}\right.$ ) (Fig. 9). In the case of the lyophilized HSA there was an endothermic peak at $220^{\circ} \mathrm{C}$, which can be due to melting, structural water evaporation or thermal decomposition. For the precipitated HSA and the HSA-IFN- $\alpha$ core-shell NPs, this peak was shifted to higher

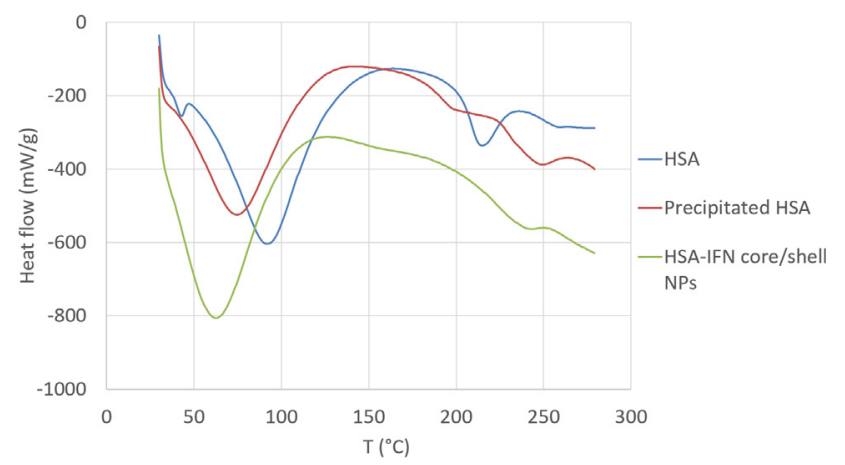

Fig. 9. DSC results of lyophilized HSA, precipitated HSA and the HSA-IFN- $\alpha$ core-shell NPs.

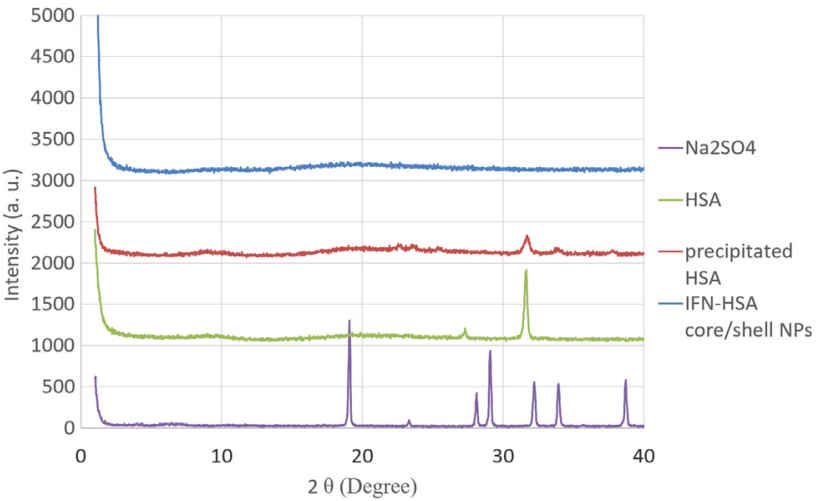

Fig. 10. The x-ray diffraction of lyophilized samples of original HSA, precipitated HSA and HSA-IFN- $\alpha$ core-shell NPs. The scattering function of the crystalline $\mathrm{Na}_{2} \mathrm{SO}_{4}$ used for precipitation is added for reference.

temperatures and the rate was decreased that can be explained by increased thermal stability.

XRD patterns of lyophilized HSA, precipitated HSA and the HSAIFN- $\alpha$ core-shell NPs (Fig. 10.) reveal the changes in HSA crystallinity in the course of the preparation procedures. The highly crystalline form of the lyophilized sample shows a pronounced peak at $2 \Theta \sim 32^{\circ}$, which decreases significantly in the process of precipitation (precipitated HSA). This decrease can also be due to the small particle size, as NPs, in general, have lower degree of crystallinity as compared to macroscopic phases of the same material. Encapsulation the precipitated protein renders it fully amorphous. Crystalline form of the salt $\mathrm{Na}_{2} \mathrm{SO}_{4}$ used for the HSA precipitation was not observed in the formulations as the specific salt peaks are absent in the HSA diffraction curves.

The morphology and the layered structure around the HSA-IFN- $\alpha$ core-shell NPs can be seen in Fig. 11. The pictures in panels (a) and (b) were obtained at different the focus positions in depth and reveal different views of the same particles. This type of focus sensitivity is generally not seen for solid particles. On the other hand, the differences in the electron density of precipitated (probably crystalline, as seen from XRD results) HSA and layered (probably non-crystalline) polyelectrolyte nanophases can explain the observed focus-sensitivity of the HSA-IFN core-shell NPs.

\subsection{Antiviral activity}

Antiviral activity of the HSA-IFN- $\alpha$ was determined in WISH tissue culture, using Vesicular Stomatitis virus and NIH, Ga23-902-530 Hu IFN- $\alpha$ standard. Double tests had been prepared. The activity of five separate samples was measured, four of which had the value of $1 \cdot 10^{5}$, and one of $\sim 1.6 \cdot 10^{5} \mathrm{IU} / \mathrm{mg}$. Compared with the activity of reference lyophilized HSA-IFN- $\alpha$ (the starting material in the HSA-IFN- $\alpha$ coreshell NP preparations) of $\sim 1.63$ to $1.92 \cdot 10^{5} \mathrm{IU} / \mathrm{mg}$, it can be established that the efficiency of the nanocapsulation is highly effective and the activity of IFN- $\alpha$ is retained.

\subsection{In vitro dissolution tests}

HSA-IFN- $\alpha$ core-shell NPs have been used for release kinetics experiments in vitro. The release kinetics results obtained this way are presented in Fig. 12 for a nanoparticle preparation. The standard deviation in the first 4 days were lower than $5.2 \%$. The highest standard deviation was $8.7 \%$ on the 6 day. The total amount of IFN- $\alpha$ was dissolved from HSA-IFN- $\alpha$ core-shell NPs after 6 day (Fig. 12). The following mathematical models were evaluated considering the dissolution profiles of the samples: Korsmeyer-Peppas, and first-order. The Table 2 shows the fitting results with these dissolution models.Fig. 13.

In the cases of first order model (Eq. (3)) the correlation coefficients 


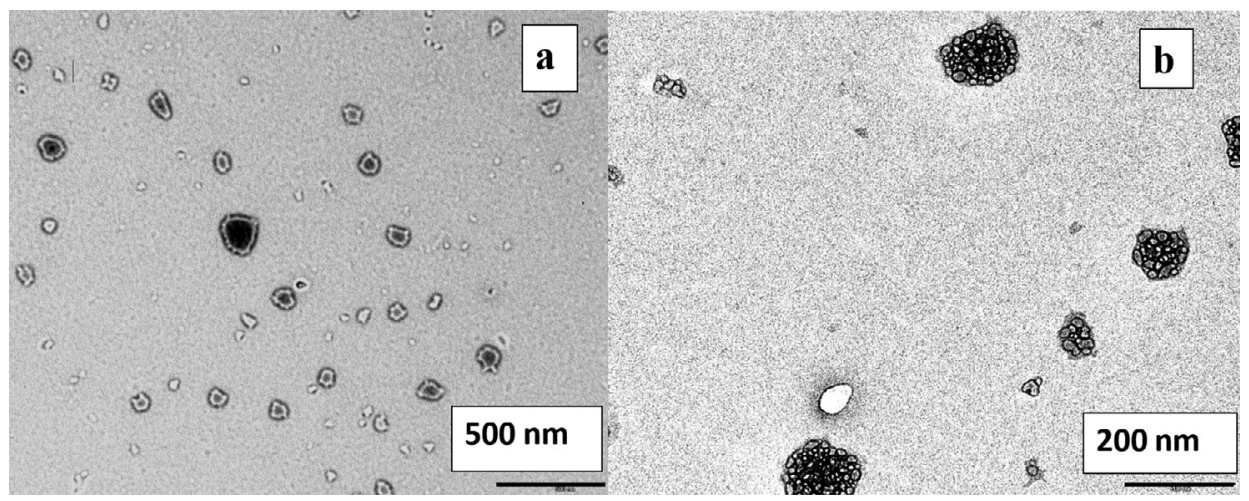

Fig. 11. The TEM pictures of HSA-IFN- $\alpha$ core-shell NPs with different focusing.

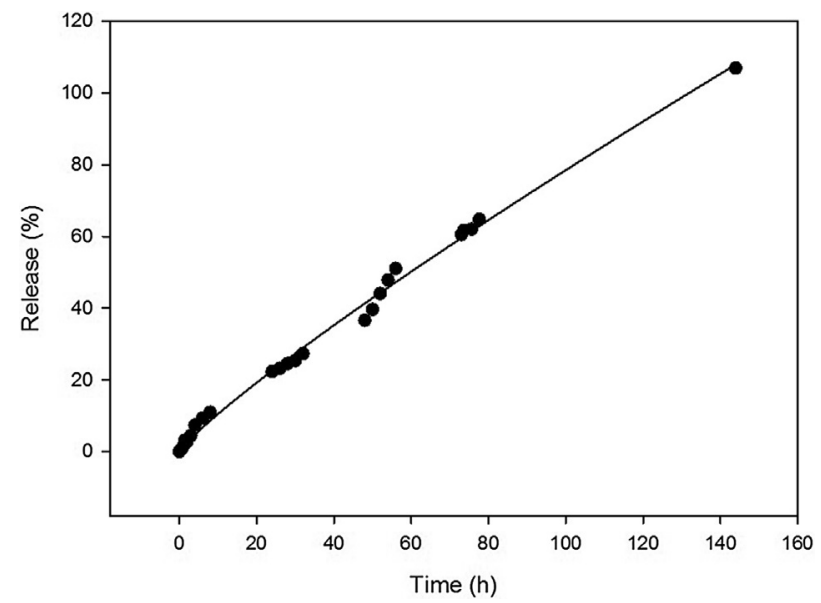

Fig. 12. HSA release from HSA-IFN- $\alpha$ core-shell NPs, measured in $\mathrm{pH}=7.4$ PBS buffer at $36^{\circ} \mathrm{C}$ in Hanson cell.

Table 2

The fitted dissolution kinetic models and the correlation coefficients.

\begin{tabular}{llll}
\hline Sorted List & $\mathrm{n}$ & $\mathrm{k}$ & $\mathrm{R}^{2}$ \\
\hline Korsmeyer-Peppas (Eq. (1)) & 0.8742 & 1.4007 & 0.9947 \\
First Order (Eq. (2)) & 1 & 0.0032 & 0.9938 \\
\hline
\end{tabular}

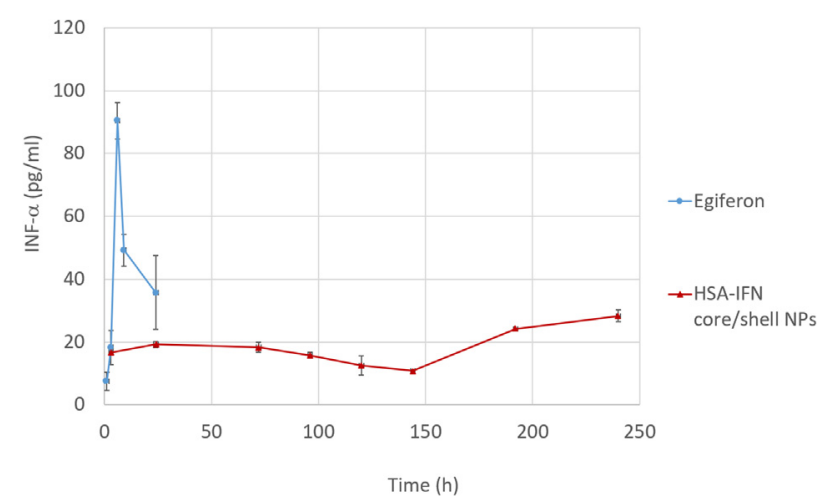

Fig. 13. Comparison of the blood IFN- $\alpha$ level of rabbits after subcutan administration of core-shell nanoparticle formulation and of the Egiferon subcutan injection.

were lower than in case of Korsmeyer-Peppas model. The values obtained during the fitting in the software were outside the expected range, therefore this model can not be applied in this case. In the case of Korsmeyer Peppas model (Eq. (4)) the $k$ was 1.4007; and the $n$ was
0.8742. The correlation coefficient $\left(R^{2}\right)$ was 0.9947 . The Korsmeyer-Peppas model was found to be the most suitable for the fitting of the drug dissolution curves in the majority of the cases, where not only diffusion but also erosion was involved in the drug release (Table 2). In our study, the release exponent (n) was $0.5<\mathrm{n}<0.89$, and the diffusion mechanism was therefore anomalous; the drug transport mechanism was non-Fickian diffusion. This indicated the coupling of erosion and diffusion mechanisms, leading to drug release controlled by multiple processes.

\subsection{Results of the in vivo study}

The IFN- $\alpha$ concentration values provided relatively constant IFN- $\alpha$ level during the 10 days of the experiment (Fig. 13.). In addition, Egiferon is not a sustained release formulation, and the extremely high IFN- $\alpha$ level $(90 \mathrm{pg} / \mathrm{mL})$ is reached within one day. With application of Graph Pad Prism software the AUC and AUMC values were calculated. The AUC was $1179 \mathrm{~h}(\mathrm{pg} / \mathrm{ml})$ and the AUMC $15390 \mathrm{~h}^{2}(\mathrm{pg} / \mathrm{ml})$ and the MRT $13.05 \mathrm{~h}$. In Table 3, the calculated values from our experiments and the values from the literature (Roferon A) were compared. In the case of HSA-IFN- $\alpha$ core-shell NPs there were no $c_{\max }$ value well defined. This NP can ensure constant IFN- $\alpha$ blood level.

\section{Conclusions}

Sustained release formulations are designed according to a variety of techniques, which are mostly expensive, complicated, requiring serious instrumentation, and, may not be fully adequate for the aim of preserving the activity of the agent, just to mention a few common difficulties. We present in this paper a novel method of core-shell nanoparticle preparation for protein drugs or protein-bound active compounds, which provides a relatively easy and inexpensive way of the formulation of sustained release products. Extension to non-protein based drugs is also conceivable. The new particle is formed by saltprecipitation of IFN- $\alpha$ containing HSA to $10 \mathrm{~nm}$ sized particles, and building up three polyelectrolyte layers on the particle surface in L-b-L strategy. The anionic polyelectrolyte is PSS and the cationic one is Chit. We have demonstrated that the particle size is in the nano-size range, and that the outer surface is negatively charged. IFN- $\alpha$ activity tests

Table 3

The kinetic parameters of human interferon- $\alpha$ in rabbit $\left(\mathrm{t}_{1 / 2}\right.$ : elimination halflife time; Cl: clearance; MRT: mean residence time).

\begin{tabular}{lll}
\hline & Human (Roferon A) & Rabbit (Core-shell HSA-IFN NP) \\
\hline $\mathrm{t}_{\max }$ (h) & 7.3 & 6 \\
$\mathrm{t}_{1 / 2}$ (h) (Eq. (4)) & 5.01 & 9.04 \\
$\mathrm{Cl}$ (ml/min/kg) & 2.79 & 2.61 \\
$\mathrm{MRT}$ (h) (Eq. (3)) & 7.63 & 13.05 \\
\hline
\end{tabular}


reveal that the formulation did not decrease IFN- $\alpha$ activity. Both in vitro and in vivo release kinetics experiments have proven slow active agent dissolution from the formulation.

After the establishment of the successful preparation technology, further improvements should be carried out in order to provide a safe formulation of the core-shell NPs. Biocompatible anionic polyelectrolytes with fully dissociated charge groups should be tested for replacing PSS. Alternatives could also be tested for replacement of the biocompatible Chit in order to vary the rate of IFN- $\alpha$ release. Scaling up of the technology to industrial size presents an additional challenge.

\section{Declaration of Competing Interest}

The authors declare that they have no known competing financial interests or personal relationships that could have appeared to influence the work reported in this paper.

\section{Acknowledgement}

This study was supported by the National Research, Development and Innovation Office, Hungary (GINOP-2.3.2-15-2016-00060).

Ministry of Human Capacities, Hungary grant 20391-3/2018/ FEKUSTRAT is acknowledged.

\section{References}

Ai, H., Pink, J.J., Shuai, X., Boothman, D.A., Gao, J., 2005. Interactions between selfassembled polyelectrolyte shells and tumor cells. J. Biomed. Mater. Res. Part A. 73, 303-312.

Balabushevitch, N.G., Sukhorukov, G.B., Moroz, N.A., Volodkin, D.V., Larionova, N.I., Donath, E., Mohwald, H., 2001. Encapsulation of proteins by layer-by-layer adsorption of polyelectrolytes onto protein aggregates: factors regulating the protein release. Biotech. Bioeng. 76, 207-213.

Borkovec, M., Papastavrou, G., 2008. Interactions between solid surfaces with adsorbed polyelectrolytes of opposite charge. Current Opin. Coll. Interf. Sci. 13, 429-437.

Caldorera-Moore, M., Vela Ramirez, J.E., Peppas, N.A., 2019. Transport and delivery of interferon- $\alpha$ through epithelial tight junctions via $\mathrm{pH}$-responsive poly(methacrylic acid-grafted-ethylene glycol) nanoparticles. J. Drug Target. https://doi.org/10.1080/ 1061186X.2018.1547732.

Caruso, F., Trau, D., Mohwald, H., Renneberg, R., 2000. Enzyme encapsulation in layerby-layer engineered polymer multilayer capsules. Langmuir 16, 1485-1488.

Chen, Y., Chen, H., Zeng, D., Tian, Y., Chen, F., Feng, J., Shi, J., 2010. Core/shell structured hollow mesoporous nanocapsules: a potential platform for simultaneous cell imaging and anticancer drugd elivery. ACS Nano 4, 6001-6013.

Dai, C., Wang, B., Zhao, H., 2005. Microencapsulation peptide and protein drugs delivery system. Coll. Surf. B: Biointerf. 41, 117-120.

de Villiers, M.M., Otto, D.P., Strydom, S.J., Lvov, Y.M., 2011. Introduction to nanocoatings produced by layer-by-layer (LbL) self-assembly. Adv. Drug Delivery Rev. 63 701-715.

Di Trolio, R., Simeone, E., Di Lorenzo, G., Buonerba, C., Ascierto, A.P., 2015. The use of interferon in melanoma patients: A systematic review. Cytokine Growth Factor Rev. 26, 203-212.

Duncana, G., Jess, T.J., Mohamed, F., Price, N.C., Kelly, S.M., van der Walle, C.F., 2005. The influence of protein solubilisation, conformation and size on the burst release from poly(lactide-co-glycolide) microspheres. J. Control. Rel. 110, 34-48.

Freag, M.S., Saleh, W.M., Abdallah, O.Y., 2018. Self-assembled phospholipid-based phytosomal nanocarriers as promising platforms for improving oral bioavailability of the anticancer celastrol. Int. J. Pharm. 535, 18-26.

Gao, F., Li, L., Fu, C., Nie, L., Chen, D., Tang, F., 2013. LHRH-PE40 fusion protein tethered silica nanorattles for imaging-guided tumor-specific drug delivery and bimodal therapy. Adv. Mater. 25, 5508-5513.

Giri, N., Tomar, P., Karwasara, V.S., Pandey, R.S., Dixit, V.K., 2011. Targeted novel surface-modified nanoparticles for interferon delivery for the treatment of hepatitis B. Acta Biochim. Biophys. Sin. 43, 877-883.

He, D., Wang, S., Lei, L., Hou, Z., Shang, P., He, X., Nie, H., 2015. Core-shell particles for controllable release of drug. Chem. Eng. Sci. 125, 108-120.

Jörgensen, L., Moeller, E.H., van de Weert, M., Nielsen, H.M., Frokjaer, S., 2006. Preparing and evaluating delivery systems for proteins. Eur. J. Pharm. Sci. 29, 174-182.

Ke, Z., Yang, L., Wu, H., Li, Z., Jia, X., Zhang, Z., 2018. Evaluation of in vitro and in vivo antitumor effects of gambogic acid-loaded layer-by-layer self-assembled micelles. Int. J. Pharm. 545, 306-317.

Kelemen, A., 2012. Dynamic force measurement in preformulation of solid dosage forms. University of Szeged $\mathrm{PhD}$ Thesis.

Khdair, A., Hamad, I., Alkhatib, H., Bustanji, Y., Mohammad, M., Tayem, R., Aiedeh, K. 2016. Modified-chitosan nanoparticles: Novel drug delivery systems improve oral bioavailability of doxorubicin. Eur. J. Pharm. Sci. 93, 38-44.

Kim, N.A., Song, K., Lim, D.G., Hada, S., Shin, Y.K., Shin, S., Jeong, S.H., 2015. Basal buffer systems for a newly glycosylated recombinant human interferon- $\beta$ with biophysical stability and DoE approaches. Eur. J. Pharm. Sci. 78, 177-189.
Korbely, A., Kelemen, A., Kása Jr, P., Pintye-Hódi, K., 2012. Effects of processing on the release profiles of matrix systems containing 5-aminosalicylic acid. AAPS Pharm. Sci. Tech. 13, 1341-1347.

Kotov, N.A., Dékány, I., Fendler, J.H., 1995. Layer-by-layer self-assembly of polyelectrolyte-semiconductor nanoparticle composite films. J. Phys. Chem. 99 13065-13069.

Kun, R., Szekeres, M., Dékány, I., 2009. Isothermal titration calorimetric studies of the pH induced conformational changes of bovine serum albumin. J. Therm. Anal. Calorim. 96, 1009-1017.

Lei, L., Wang, S., Wu, H., Ju, W., Peng, J., Qahtan, A.S., Chen, C., Lu, Y., Zhang, X., Nie, H., 2014. Optimization of release pattern of FGF-2andBMP-2forosteogenic differentiation of low-population density hMSCs. J. Biomed. Mater. Res. A. 103, 252-261.

Li, J.J., Yang, Y.Y., Yu, D.G., Du, Q., Yang, X.L., 2018. Fast dissolving drug delivery membrane based on the ultra-thin shell of electrospun core-shell nanofibers. Eur. J. Pharm. Sci. 122, 195-204.

Liu, C., Kou, Y., Zhang, X., Dong, W., Cheng, H., Mao, S., 2019. Enhanced oral insulin delivery via surface hydrophilic modification of chitosan copolymer based self-assembly polyelectrolyte nanocomplex. Int. J. Pharm. 554, 36-47.

Martinek, T.A., Hetényi, A., Fülöp, L., Mándity, I.M., Tóth, G.K., Dékany, I., Fülop, F., 2006. Residue-controlled intrinsic self-assembly of b-peptides into tertiary structure motifs. Angew. Chem. Int. 45, 2396-2400.

Möhwald, H., 2000. From Langmuir Monolayers to Nanocapsules. Coll. Surf. A. 171, 25-31.

Müller, M., Kessler, B., Adler, H.J., Lunkwitz, K., 2004. Reversible switching of protein uptake and release at polyelectrolyte multilayers detected by ATR-FTIR spectroscopy. Macromol. Symp. 210, 157-164.

Narayanan, S., Pavithran, M., Viswanath, A., Narayanan, D., Mohan, C.C., Manzoor, K., Menon, D., 2014. Sequentially releasing dual-drug-loaded PLGA-casein core/shell nanomedicine: design, synthesis, biocompatibility and pharmacokinetics. Acta Biomaterialia 10, 2112-2124.

Nie, H., Dong, Z., Arifin, D.Y., Hu, Y., Wang, C.H., 2010a. Core/shell microspheres via coaxial electrohydrodynamic atomization for sequential and parallel release of drugs. J. Biomed. Mater. Res. A. 95, 709-716.

Nie, H., Fu, Y., Wang, C.H., 2010b. Paclitaxel and suramin-loaded core/shell microspheres in the treatment of brain tumors. Biomaterials 31, 8732-8740.

Peppas, N.A., 1985. Analysis of Fickian and non-Fickian drug release from polymers. Pharm. Acta Helv. 60, 110-111.

Pollok, S., Ginter, T., Günzel, K., Pieper, J., Henke, A., Stauber, R.H., Reichardt, W., Krämer, O.H., 2013. Interferon alpha-armed nanoparticles trigger rapid and sustained STAT1-dependent anti-viral cellular responses. Cellular Signalling 25, 989-998.

Radtchenko, I.L., Sukhorukov, G.B., Leporatti, S., Khomutov, G.B., Donath, E., Möhwald, H., 2000. Assembly of alternated multivalent ion/polyelectrolyte layers on colloidal particles. stability of the multilayers and encapsulation of macromolecules into polyelectrolyte capsules. J. Coll. Interf. Sci. 230, 272-280.

Sedeky, A.S., Khalil, I.A., Hefnawy, A., El-Sherbiny, I.M., 2018. Development of core-shell nanocarrier system for augmenting piperine cytotoxic activity against human brain cancer cell line. Eur. J. Pharm. Sci. 118, 103-112.

Shiau, K.S., Chen, T.L., 1997. Initial protein concentration effects on precipitation by salt. Biotech. Bioeng. 53, 202-206.

Shih, Y.C., Prausnitz, J.M., Blanch, H.W., 1992. Some characteristics of protein precipitation by salts. Biotech. Bioeng. 40, 1155-1164.

Shkodra-Pula, B., Grune, C., Traegera, A., Vollrath, A., Schubert, S., Fischerb, D., Schubert, U.S., 2019. Effect of surfactant on the size and stability of PLGA nanoparticles encapsulating a protein kinase C inhibitor. Int. J. Pharm. https://doi.org/10. 1016/j.ijpharm.2019.05.072.

Sinha, V.R., Trehan, A., 2003. Biodegradable microspheres for protein delivery. J. Control. Rel. 90, 261-280.

Sukhorukov, G.B., Donath, E., Lichtenfeld, H., Knippel, E., Knippel, M., Budde, A., Möhwald, H., 1998. Layer-by-layer self assembly of polyelectrolytes on colloidal particles. Coll. Surf. A. 137, 253-266.

Varga, N., Benkő, M., Sebők, D., Dékány, I., 2014. BSA/polyelectrolyte core-shell nanoparticles for controlled release of encapsulated ibuprofen. Coll. Surf. B: Biointerf. 123, 616-622.

Varga, N., Hornok, V., Sebók, D., Dékány, I., 2016. Comprehensive study on the structure of the BSA from extended-toaged form in wide (2-12) pH range. Int. J. Biol. Macromol. 88, 51-58.

Volodkin, D.V., Larionova, N.I., Sukhorukov, G.B., 2004. Protein encapsulation via porous $\mathrm{CaCO}_{3}$ microparticles templating. Biomacromol. 5, 1962-1972.

Wang, H., Wang, S., Liao, Z., Zhao, P., Su, W., Niu, R., Chang, J., 2012. Folate-targeting magnetic core-shell nanocarriers for selective drug release and imaging. Int. J. Pharm. 430, 342-349.

Wu, H., Zhang, S., Zhang, J., Liu, G., Shi, J., Zhang, L., Cui, X., Ruan, M., He, Q., Bu, W., 2011. A hollow-core, magnetic, and mesoporous double-shell nanostructure: in situ decomposition/reduction synthesis, bioimaging, and drug-delivery properties. Adv. Funct. Mater. 21, 1850-1862.

Yang, X., Li, Z., Li, M., Ren, J., Qu, X., 2013. Fluorescent protein capped mesoporous nanoparticles for intracellular drug delivery and imaging. Chem. Eur. J. 19, 15378-15383.

Yu, M.Z., Pang, W.H., Yang, T., Wang, J.C., Wei, L., Qiu, C., Wu, Y.F., Liu, W.Z., Wei, W., Guo, X.Y., Zhang, Q., 2016. Systemic delivery of siRNA by T7 peptide modified coreshell nanoparticles for targeted therapy of breast cancer. Eur. J. Pharm. Sci. 92 , 39-48.

Zashikhina, N.N., Volokitina, M.V., Korzhikov-Vlakh, V.A., Tarasenko, I.L, Lavrentieva, A., Scheper, T., Rühl, E., Orlova, R.V., Tennikova, T.B., Korzhikov -Vlakh, E.G., 2017 Self-assembled polypeptide nanoparticles for intracellular irinotecan delivery. Eur. J. Pharm. Sci. 109, 1-12.

Zhao, M., Lee, S.H., Song, J.G., Kim, H.Y., Han, H.K., 2018. Enhanced oral absorption of sorafenib via the layer-by-layer deposition of a $\mathrm{pH}$-sensitive polymer and glycol chitosan on the liposome. Int. J. Pharm. 544, 14-20. 